\title{
A produção de carne e leite a base de pastagens começa por sementes de qualidade
}

\author{
Cássio Felipe Lopes', Cassiano Eduardo Pinto², Tiago Celso Baldissera², Gustavo Martins da Silva ${ }^{3}$, \\ Diego Gindri ${ }^{4}$ e Fabio Cervo Garagorry ${ }^{3}$
}

\begin{abstract}
Resumo - As pastagens de inverno são um importante componente dos sistemas pecuários no sul do Brasil, oportunizando a produção de carne e leite a custos competitivos. A qualidade de sementes é fundamental para o estabelecimento de pastos produtivos, com alto potencial e livre de contaminação de patógenos e plantas indesejáveis. O objetivo foi avaliar a qualidade de sementes de forrageiras de inverno adquiridas por produtores rurais no Planalto Catarinense, no verão/outono de 2017 e 2019. Foram amostrados 78 lotes de sementes de forrageiras no mercado local em 12 municípios da região. Parâmetros de germinação, pureza, outras sementes e material inerte foram analisados em laboratório de análise de sementes credenciado no Ministério da Agricultura Pecuária e Abastecimento. Mais de $67 \%$ dos lotes de sementes analisadas estão abaixo do que preconiza a legislação vigente. Isto compromete o estabelecimento e a produção, prejudicando a rentabilidade dos pecuaristas.
\end{abstract}

Termos para indexação: Valor cultural; análise de pureza; teste de germinação; prejuízo.

\section{Beef and milk production starts with quality seeds}

Abstract - Winter pastures are an important component of livestock systems in southern Brazil. It provides meat and milk production at low costs. The seeds quality is fundamental for establishment of productive forages, with high potential and free contamination of undesirable pathogens and weeds. The objective was to evaluate the seeds quality of winter forage acquired by ranchers in highlands region of Santa Catarina State. It were sampled 78 lots of seeds in the local market in 12 municipalities, collected during summer and autumn of 2017 and 2019. Parameters were germination, purity, other seeds and inert material analyzed in laboratory homologated by the Ministry of Agriculture, Livestock and Supply. More than $67 \%$ of the analyzed seeds lots are below what the current legislation standards. This compromises the establishment, the production, and profitability of the ranchers.

Index terms: Cultural value, purity analysis; germination test; financial loss.

As cadeias produtivas de corte e leite no sul do Brasil têm sua base alimentar estruturada em forrageiras hibernais, destacando-se o azevém, a aveia, e os trevos branco e vermelho. A utilização de sementes de alta qualidade constitui-se em elemento decisivo (BIN et al., 2018) para a implantação de pastos produtivos, otimizando a produção animal.

A qualidade da semente é definida como o conjunto de atributos genéticos, físicos, fisiológicos e sanitários que influenciam na capacidade de o lote originar um cultivo uniforme, constituído de plantas vigorosas e representativas do cultivar, livre de plantas invasoras ou indesejáveis (POPINIGIS, 1985). No Brasil, o Ministério da Agricultura Pecuária e Abastecimento (Mapa) é o órgão responsável pela rede de laboratórios agropecuários oficiais, além de atribuir, uniformizar e oficializar os métodos para realização de análises de sementes, através das Regras de Análise de Sementes (RAS) (BRASIL, 2009). Para cada cultivo, o Mapa publica uma normativa específica, na qual ficam estabelecidos as normas de produção e os padrões de identidade e qualidade de sementes das espécies forrageiras. Nestas normativas, estão os padrões de campo para a produção de sementes de qualidade e identidade.

Para a avaliação da qualidade de uma semente forrageira utiliza-se o índice do valor cultural (VC), sendo definido pelo produto entre a germinação e o grau de pureza da amostra (Referên- cia). A germinação, sob ponto de vista da análise laboratorial, é definida como a emergência e o desenvolvimento das estruturas essenciais do embrião, manifestando sua capacidade para dar origem a uma plântula normal, sob condições ótimas (CARAMBULA, 1997). Já a determinação da composição percentual por peso e a identidade das diferentes espécies de sementes e do material inerte das amostras são avaliadas através da análise de pureza (BRASIL, 2009). É importante destacar que os lotes de sementes que não atingem os percentuais mínimos de germinação ou a pureza exigidos pela legislação têm a sua comercialização proibida como semente (BRASIL, 2009).

A semente de qualidade deve ter or

Recebido em 13/5/2020. Aceito para publicação em 28/7/2020.

${ }^{1}$ Acadêmico do Curso de Agronomia, Udesc/CAV, campus Lages, SC, e-mail: cassiolopes_@hotmail.com;

${ }^{2}$ Eng.-agr., Dr., Estação Experimental de Lages (Epagri/EEL), Lages, SC, e-mail:cassiano@epagri.sc.gov.br, tiagobaldissera@epagri.sc.gov.br

${ }^{3}$ Eng.-agr., Dr., Embrapa Pecuária Sul, Bagé, RS, e-mail:gustavo.silva@embrapa.br, fabio.garagorry@embrapa.br.

${ }^{4}$ Eng.-agr. Dr., Cidasc - Gerência Regional de Lages, Lages, SC, e- mail: diegogindri@gmail.com 
componente genético que irá expressar no seu potencial produtivo, nas suas características agronômicas, na reação a doenças e pragas, entre outras. Além disso, a pureza física deve abranger todas as sementes pertencentes à espécie em exame, sendo determinada pelo grau e pelo tipo de contaminantes presentes no lote. A germinação é um atributo de qualidade fisiológica e, em tecnologia de sementes, é definida como a emergência e o desenvolvimento das estruturas essenciais do embrião, manifestando sua capacidade para dar origem a uma plântula normal, sob condições ambientais favoráveis (PESKE\& BARROS, 2003), desejáveis em um lote de sementes. A boa semente não deve veicular patógenos capazes de afetar a emergência e o vigor das plântulas ou constituir inóculo primário para o desenvolvimento de epidemias e consequente redução no rendimento do pasto.

Sabe-se que a produção de sementes de espécies forrageiras de clima temperado ainda apresenta sérios problemas e limitações. Constata-se que muitos produtores de sementes não investem mais porque os consumidores não valorizam a qualidade, e isso desabastece o mercado para quem procura sementes certificadas. Os prejuízos decorrentes desse ciclo vicioso são evidentes para o setor primário na Região Sul. Estudos conduzidos por Melo \& Barros (2005) e Silva et al. (2011) demonstraram um mercado de sementes forrageiras desorganizado, com vários processos informais que concorrem para a escassez de cultivares e para baixa qualidade de sementes comercializadas na Região Sul.

O presente trabalho foi elaborado visando avaliar a qualidade de sementes forrageiras de clima temperado adquiridas pelos produtores da Serra Catarinense e tem os seguintes objetivos: a) Caracterizar a qualidade física e fisiológica de sementes comercializadas por produtores rurais ou casas comerciais em 12 municípios do Planalto Catarinense nos anos de 2017 e 2019; b) Estimar as perdas na produção de forragem e na produção animal em razão do uso de sementes com qualidade inferior às recomendadas pela legislação.

Foram coletadas amostras de 49 lotes de sementes em 2017 adquiridas no mercado local por produtores rurais e 29 lotes de sementes em 2019 compradas em lojas de insumos agropecuários, nos municípios de Água Doce, Capão Alto, Correia Pinto, Lages, Otacílio Costa, Painel, Palmeira, São Joaquim, São José do Cerrito, Urubici e Urupema, em Santa Catarina. As sementes compreenderam aveia-branca (Avena sativa L.), aveia-preta (Avena stigosa Schreb.), azevém (Lolium multiflorum Lam.), capim-lanudo (Holcus lanatus L.), centeio (Secale cereale), cornichão (Lotus corniculatus L.), capim-dos-pomares (Dactilys glomerata L.), festuca (Festuca arundinacea Schreb.), trevo-branco (Trifolium repens L.) e trevo vermelho (Trifolium pratense L.).

As amostras foram encaminhadas para laboratórios credenciados no $\mathrm{Mi}$ nistério da Agricultura, seguindo as Regras de Análise de Sementes (BRASIL, 2009), sendo avaliados os parâmetros de germinação e pureza, outras sementes e material inerte presente na amostra.

Foi realizada uma análise exploratória dos dados dos lotes reprovados para a comercialização por meio de planilha Excel. O valor cultural dos lotes (VC), a estimativa de perdas do potencial produtivo das pastagens e o cálculo de prejuízo foram simulados a partir dos resultados dos laudos de análises. As fórmulas utilizadas são descritas a seguir. Para o cálculo do índice do VC foi utilizada a seguinte equação: Valor cultural $=($ Germinação $\times$ Pureza $) / 100$. O cálculo do prejuízo foi realizado através da seguinte equação: Prejuízo (ha) = (VC das amostras)*(VC legal)/VC legal.

O número de lotes analisados para cada pasto, os parâmetros sementes puras, outras sementes, material inerte e percentagem de germinação para os dois anos avaliados podem ser visualizados na Tabela 1.

Nos dois anos avaliados, $83 \%$ das amostras de aveia-branca foram reprovadas em pelo menos um dos padrões estabelecidos na legislação. Os lotes de aveia-preta foram aprovados em $71 \%$ dos testes no ano de 2017. Para azevém, 83\% das amostras de 2017 reprovaram, sendo que em germinação $81,23 \%$ foram reprovados, seguido de pureza $(13,6 \%)$ e outras sementes $(81,2 \%)$. No ano de 2019, os lotes de sementes de azevém foram reprovados pela pureza, com valores abaixo de $95 \%$ e alguns lotes reprovados pela germinação, com valores abaixo de $70 \%$ com médias de $27,6 \%$, estando bem abaixo dos $70 \%$ exigidos pela legislação. Em 2017, o lote avaliado de capim-lanudo foi aprovado, porém em 2019, as percentagens médias de pureza das sementes de capimlanudo foram $99,7 \%$, contudo reprovados pela baixa germinação $(27,9 \%)$.

Em 2017, o centeio e o capim-dospomares foram aprovados em todos os testes, sendo aptos à comercialização, segundo a legislação. Já a amostra de cornichão reprovou na germinação. Em 2019 as sementes de capim-dos-pomares apresentaram baixo percentual de pureza $(70,4 \%)$, elevada participação de outras sementes (27\%), mas com parâmetro aceitável de germinação (acima de $70 \%$ ). Os teores médios de pureza para as sementes de festuca em 2019 foram $95,2 \%$, sendo condenadas pela baixa germinação. Nos dois anos avaliados, os lotes de trevo-branco foram reprovados em $75 \%$ das amostras para o parâmetro germinação, e em 2019 as amostras também estavam fora da legislação no critério outras sementes, com valores superiores ao recomendado pela legislação. O trevo-vermelho reprovou no ano de 2017 em 25\% das amostras no parâmetro de germinação. Em 2019, foram condenadas no critério de pureza, com valores abaixo de $95 \%$.

Aplicando o que define a legislação (BRASIL, 2016), apenas 37,3\% dos lotes avaliados são classificados como sementes e estariam aptos para comercialização em 2017. Considerando os dois anos, apenas $32,15 \%$ dos lotes analisados estariam aptos à comercialização.

Foram encontrados 31 e 25 gêneros de outras espécies contaminando as amostras de sementes em 2017 e 2019, respectivamente. Amostras livres de contaminação foram 30,61\% em 2017 e $13,80 \%$ em 2019 . Um problema oculto quando sementes sem certificação são adquiridas é a contaminação, pois outras sementes podem ser cultivadas, silvestres ou nocivas, que competem por espaço, luz, água e nutrientes. Plantas indesejáveis possuem alta capacidade de competição e, por não apresentarem qualidade forrageira, não são consumi- 
Tabela 1. Avaliação de lotes de sementes reprovados de espécies forrageiras hibernais em 12 municípios do Planalto Catarinense nos anos de 2017 e 2019

Table 1. Failed lots of cool season seeds acquired by ranchers in 12 municipalities in Planalto Catarinense in the year of 2017 e 1019

\begin{tabular}{|c|c|c|c|c|c|c|c|}
\hline Espécie & Ano & Pureza \% & $\begin{array}{c}\text { Outras } \\
\text { espécies \% }\end{array}$ & $\begin{array}{l}\text { Material } \\
\text { inerte \% }\end{array}$ & Germinação \% & VC Real \% & VC Legal \% \\
\hline \multirow{2}{*}{ Aveia-branca } & $2017(4)^{*}$ & 95,90 & 2,70 & 0,40 & 71,00 & 68 & \multirow{2}{*}{78,40} \\
\hline & 2019 (1) & 91,80 & 3,40 & 4,80 & 57,00 & 52,30 & \\
\hline \multirow{2}{*}{ Aveia-preta } & 2017 (2) & 99,40 & 0,25 & 0,30 & 77,00 & 76,60 & \multirow{2}{*}{76,80} \\
\hline & $2019(4)$ & 95,20 & 4,30 & 0,70 & 48,50 & 48,20 & \\
\hline \multirow{2}{*}{ Azevém } & 2017 (19) & 96,20 & 1,30 & 2,50 & 27,20 & 26,20 & \multirow{2}{*}{66,50} \\
\hline & 2019 (11) & 94,00 & 1,20 & 4,80 & 29,30 & 27,60 & \\
\hline \multirow{2}{*}{ Capim-lanudo } & $2017(1)$ & 98,80 & 0,60 & 0,60 & 57,00 & 56,30 & \multirow{2}{*}{54,00} \\
\hline & 2019 (1) & 99,70 & 0,00 & 0,30 & 28,00 & 27,90 & \\
\hline \multirow{2}{*}{ Cornichão } & 2017 (1) & 98,10 & 0,50 & 1,40 & 65,00 & 63,70 & \multirow{2}{*}{66,50} \\
\hline & 2019 & - & - & - & - & & \\
\hline \multirow{2}{*}{ Festuca } & 2017 (1) & 76,70 & 21,00 & 2,20 & 72,00 & 55,20 & \multirow{2}{*}{63.00} \\
\hline & $2019(2)$ & 95,15 & 0,05 & 4,80 & 31,00 & 29,40 & \\
\hline \multirow{2}{*}{ Trevo-branco } & 2017 (3) & 99,50 & 0,16 & 0,33 & 62,00 & 61,60 & \multirow{2}{*}{76,00} \\
\hline & 2019 (3) & 97,60 & 1,75 & 0,65 & 62,50 & 61,00 & \\
\hline \multirow{2}{*}{ Trevo-vermelho } & 2017 (1) & 99,90 & 0,00 & 0,10 & 22,00 & 22,00 & \multirow{2}{*}{66,50} \\
\hline & $2019(4)$ & 89,80 & 0,33 & 9,80 & 73,00 & 71,40 & \\
\hline
\end{tabular}

* Número de amostras avaliadas reprovadas no ano.

** Total de amostras avaliadas; Aveia-branca 6; aveia-preta 13; Azevém 39; Capim-lanudo 2; Centeio 1; Cornichão 1; Dactilys 2; Festuca 4; Trevo-branco 8; Trevo-vermelho 9.

das pelo gado e acabam dominando a comunidade vegetal. Desta forma, oneram o produtor pela necessidade de controle para erradicação.

Dos lotes contaminados, foram encontradas 2,70 e 2,60 sementes/lote para 2017 e 2019 de outras espécies, respectivamente. As espécies encontradas, como corda-de-viola (Ipomea $s p$ ), língua-de-vaca (Rumex sp), e nabiça (Raphanus raphanistrum L.), são de alto potencial invasivo, e a flor-roxa (Echium plantagineum L.) é tóxica para bovinos e equinos.

A pouca atenção dada à qualidade de sementes reflete-se na condição atual de muitas pastagens, as quais apresentam falhas no estabelecimento, encurtando o período de utilização, o que prejudica a produção de forragem
(SILVA, 2011). Nessa linha de análise não foi considerado o prejuízo decorrente do baixo vigor (das sementes que ainda estão vivas) e todos os impactos negativos para o sistema de produção do mau estabelecimento da pastagem. Como degradação de solo pela falta de cobertura, não fixação de carbono pelas plantas e não reciclagem de nutrientes pelos animais, impactos negativos para a saúde dos animais, ou mesmo ajustes que o produtor precisaria fazer para compensar a falta de forragem (fornecer mais silagem, replantar ou dispor de outra pastagem, alterar o manejo previsto dos animais, entre outros).

A elevação dos preços dos insumos tem reduzido as margens de remuneração dos pecuaristas, que buscam uma diminuição de custos através da compra de sementes baratas, o que pode trazer consequências sérias, como mostram os dados supracitados. Além disso, os produtores não fazem a conta do preço real pago pelas sementes puras e viáveis e da possível perda do potencial produtivo das pastagens. É importante salientar que a recomendação técnica de semeadura para cada pasto leva em conta sementes com pureza e germinação de $100 \%$, ou seja, deve-se corrigir o valor cultural (VC) para ajustar a quantidade necessária de sementes.

Quando se analisa o VC, percebe-se que o preço real das sementes é muito maior, pois é necessário maior quantidade de sementes para estabelecer uma adequada população de plantas. Os resultados do VC das análises estão descritos na Tabela 1. De acordo 
com laudos das amostras coletadas na região, para a aveia-branca, seria necessário o dobro de sementes para estabelecer uma população de plantas adequada. Destaca-se, porém, que tal procedimento é agronomicamente incorreto. Desta forma, o preço real da semente foi de $\mathrm{R} \$ 1,62 \mathrm{~kg}^{-1}$, apesar de o produtor ter desembolsado $\mathrm{R} \$ 0,85$ $\mathrm{kg}^{-1}$. Em alguns lotes de azevém, o valor cultural foi de zero, ou próximo a $30 \%$, o que inviabilizaria o estabelecimento adequado e a produção de pasto. A falta de sementes puras e viáveis faz com que a área não se estabeleça e não cubra o solo totalmente, o que leva à redução do potencial produtivo por falta de plantas na área, resultando em prejuízos. O prejuízo direto leva em conta a área da lavoura que permaneceu sem plantas para produção de forragem.

A aveia-branca, o capim-lanudo e a festuca foram as espécies forrageiras com maiores prejuízos por hectare (Tabela 2), deixando 33, 48 e 53\% da área semeada sem plantas, respectivamente.

As pastagens cultivadas de inverno apresentaram um potencial de transformar $10 \mathrm{~kg}$ de matéria seca de pasto em $1 \mathrm{~kg}$ de peso vivo (PV/animal) em bovinos de alto potencial genético. Desta forma, se convertermos a perda de potencial de produção de pasto em produção de carne, a baixa qualidade das sementes traz prejuízos superiores a 119,310 , e $281 \mathrm{~kg}$ de peso vivo por hectare, para aveia-branca, capim-lanudo e festuca, respectivamente. Quando se multiplica pelo valor de mercado do boi gordo de $\mathrm{R} \$ 6,50 \mathrm{Kg} \mathrm{PV}^{-1}$, a perda de potencial produtivo do capim-lanudo pode chegar ao valor de $\mathrm{R} \$ 2.015,71 \mathrm{ha}^{-1}$.

Nos últimos anos o mercado de sementes tem uma ampla variabilidade de preços e cultivares disponíveis, o que torna a decisão de compra mais complexa. Entretanto, o produtor deve ficar atento, pois a produção de carne e leite começa por uma semente de qualidade.

As sementes avaliadas apresentaram baixa qualidade necessitando atenção dos pecuaristas na aquisição. A empresa de fiscalização agropecuária de SC tem se esforçado na fiscalização da qualidade das sementes comercializadas no Estado, entretanto é fundamental que o produtor adquira somente sementes legais, com nota fiscal, de comerciantes registrados, embaladas em sacarias identificadas, etiquetadas e acompanhadas do termo de conformidade ou certificado de sementes emitido pelo produtor das sementes. O termo de conformidade ou certificado de sementes traz as informações do boletim de análise do lote das sementes, sendo a garantia do comprador quanto aos padrões mínimos estabelecidos. Ademais, o produtor pode coletar amostra das sementes compradas e encaminhar ao laboratório, para verificação da qualidade. Esta é uma prática de baixo custo, mas pouco comum entre os produtores.

Tabela 2. Prejuízo por hectare (ha), perda na produção de forragem (kg MS/ha), produção de carne (kg PV/ha), e leite (kg Leite/ha) em função do uso de sementes de baixa qualidade Table 2. Loss per hectare (ha), loss of forage production ( $\mathrm{kg} \mathrm{DM} / \mathrm{ha}$ ), beef production ( $\mathrm{kg}$ $\mathrm{LW} / \mathrm{ha}$ ), and dairy production ( $\mathrm{kg}$ Milk/ha) in function of poor quality seeds

\begin{tabular}{|c|c|c|c|c|}
\hline Espécie & $\begin{array}{l}\text { Prejuízo } \\
\text { (ha) }\end{array}$ & $\begin{array}{l}\text { Perda de forragem } \\
\qquad\left(\mathrm{kgMS} \mathrm{ha}^{-1}\right)\end{array}$ & $\begin{array}{l}\text { Perda Bov. Corte } \\
\quad\left(\text { kgPV ha }^{-1}\right)\end{array}$ & $\begin{array}{l}\text { Perdas Bov. Leite } \\
\left(\mathrm{kgL} \mathrm{ha}^{-1}\right)\end{array}$ \\
\hline Aveia-branca & $-0,33$ & $-1196,94$ & $-119,69$ & $-1196,94$ \\
\hline Aveia-preta & $-0,21$ & $-1093,27$ & $-109,33$ & $-1093,27$ \\
\hline Azevém & $-0,17$ & $-1095,85$ & $-109,58$ & $-1095,85$ \\
\hline Lanudo & $-0,48$ & $-3101,1$ & $-310,11$ & $-3101,1$ \\
\hline Dactylis & $-0,2$ & $-1014,67$ & $-101,47$ & $-1014,67$ \\
\hline Festuca & $-0,53$ & $-2813,14$ & $-281,31$ & $-2813,14$ \\
\hline Trevo-Branco & $-0,07$ & -183 & $-18,3$ & -183 \\
\hline
\end{tabular}

\section{Agradecimentos}

Apoio financeiro do Projeto Sementec/Embrapa Pecuária Sul e ao CNPq Project NEXUS II, MCTI/CNPq no. 441396/2017-8 por financiar parte da pesquisa. Aos colegas Ana P. Schlichting, Newton B. da Costa Jr, Ulisses de A. Córdova, Marcelino Campagnaro, Élen R. N. C. Ferreira, Clayrton A. C. da Silveira, Luiz T. de Souza, e Simone S. Werner da Epagri pela colaboração no trabalho.

\section{Referências}

BIN, A.R.O.; SCHERER, M.R.; CARBONERA, R. Qualidade fisiológica de sementes de aveia preta produzidas na região noroeste do RS. In: COMISSÃO DE PESQUISA DA AVEIA, 38., 2018, Ijuí. Anais[...] ljuí, Março de 2018. p.416-420.

BRASIL. Ministério da Agricultura, Pecuária e Abastecimento. Regras para análise de sementes. Brasília, DF, 2009. 399p. (Mapa/ ACS, ISBN 978-85-99851-70-8).

BRASIL. Ministério da Agricultura Pecuária e Abastecimento. Instrução Normativa Número 44, de 22 de novembro de 2016. Diário Oficial da União, Número 230. ISSN 16777042. Brasília, DF. Dezembro de 2016.

CARAMBULA, M. Pasturas Naturales Mejoradas. Montevideo, Uruguay. 1997. 524p. Editorial Agropecuária Hemisfério Sur S.R.L.

MELO, P.T.B.S.; BARROS, C.S.A. Situação da produção de sementes de trevo branco (Trifolium repens L.), cornichão (Lotus corniculatus L.) e Lotus anual (Lotus subbiflorus Lag.) no Rio Grande do Sul. Revista Brasileira de Agrociência, Pelotas, v.11, n.1, p.13-18, 2005.

PESKE, S.T.; BARROS, C.S.A. Produção de Sementes. In: PESKE, S.T.; ROSENTHAL, M.; ROTA, G. (Ed.). Sementes: fundamentos científicos e tecnológicos. Pelotas: UFPel, 1a edição, 2003. p.12 - 93.

POPINIGIS, F. Fisiologia da semente. 2.ed. Brasília: AGIPLAN, 1985. 289p.

SILVA, G.M. da; MAIA, M.B.; MAIA, M. de S. Qualidade de sementes forrageiras de clima temperado. Bagé, RS: Embrapa Pecuária Sul, Documentos, n.119. EMBRAPA, 2011. 22p. 